\title{
From inequality to equality: Evaluating normative justifications for affirmative action as racial redress
}

\author{
Susan Hall \& Minka Woermann
}

\begin{abstract}
We investigate whether, and to what extent, Nozick's entitlement theory and Rawls's theory of justice as fairness can normatively ground affirmative action policies. Our findings are that, whereas the Nozickean project offers no guidance for large-scale redress, the Rawlsian position supports affirmative action as redress, but only in its softer forms. Therefore, if one accepts the assumptions of equal liberty and fairness upon which Rawls's theory is based, one is left with two alternatives: either to reject Rawls's theory because it fails to support quota systems, or to accept Rawls's theory and reject quota systems as a legitimate form of redress. We argue for the latter option.
\end{abstract}

\section{Keywords:}

Rawls, affirmative action, apartheid, quota systems, principle of rectification, justice as fairness, procedural justice, diversity

\author{
Susan Hall * \\ Department of Philosophy \\ Stellenbosch University \\ Private Bag X1 \\ Matieland \\ 7602 \\ South Africa \\ E: shall@sun.ac.za \\ Minka Woermann \\ Department of Philosophy \\ Stellenbosch University \\ Private Bag X1 \\ Matieland \\ 7602 \\ South Africa \\ E:minka@sun.ac.za
}

\section{INTRODUCTION}

Twenty years after the advent of democracy, and despite sustained economic growth during the post-apartheid period (Lundahl \& Petersson, 2009:22), South Africa remains rent by vast inequalities in income, education, and access to resources and services. While there is some evidence that there has been progress in reducing inequality between population groups in areas such as income distribution (Van der Berg, 2011:128; Lundahl \& Petersson, 2009:8) and access to basic services (Seekings, 2007:22), the pace of change remains frustratingly slow, and levels of interracial inequality remain extremely high (Leibbrandt et al., 2012:33).

In particular, the pattern of income distribution and employment in South Africa remains tied to the hierarchy of racial classification institutionalised by the apartheid government. Whites continue to top the pay scale, followed

Susan Hall is a lecturer in the Department of Philosophy and the Centre for Applied Ethics at Stellenbosch University. Her PhD, completed in 2012, focused on the ethics of human enhancement. She currently teaches environmental ethics, business ethics and bioethics.

Minka Woermann is a senior lecturer in the Department of Philosophy, and is Head of the Unit for Business Ethics and Public Integrity in the Centre for Applied Ethics at Stellenbosch University. She is the editor-inchief of the African Journal of Business Ethics and the author of On the (im)possibility of business ethics: Critical complexity, deconstruction, and implications for understanding the ethics of business (Springer, 2013).

* Author to whom correspondence should be addressed 
by Indians and coloureds, with black aggregate earnings remaining the lowest (Van der Berg, 2011:121-122). According to the South African Institute of Race Relations, in 2011, "the median monthly wage for African earners was R2 380, for coloured earners R3 030, for Indian earners R6 800, and for white earners R10 000" (2013a) and black employees remained woefully underrepresented in senior management (2013b:254). Levels of unemployment follow similar patterns - in 2009, "narrow unemployment was 28.8 per cent for blacks, against 4.6 per cent for whites; coloureds (21.6\%) and Indians (12.7\%) occupied intermediate positions" (Van der Berg, 2011:127). ${ }^{1}$ It is indisputable that the racial discrimination legally entrenched by the colonial and Union governments ${ }^{2}$ and under the apartheid regime ${ }^{3}$ contributed greatly to this pattern of inequality (Van der Berg, 2011:120; Seekings, 2007:2).

Addressing these disparities in income and employment has been a major concern of government since 1994, and affirmative action has been introduced as part of an arsenal of socioeconomic policies directed towards this goal, given that "most income inequality originates in the labour market, through the distribution of jobs and the wage formation process" (Van der Berg, 2011:133). Notably, affirmative action, under the Employment Equity Act of 1998, is explicitly referred to as a form of "redress" for the "disparities in employment, occupation and income" that have resulted from "apartheid and other discriminatory laws and practices” (1998:1).

1 In 2011, blacks made up $79.2 \%$ of the national population, coloureds $8.9 \%$, Indians $2.5 \%$, and whites $8.9 \%$ (Van der Berg, 2011:17).

2 For example, the Mines and Works Act (1911), the Natives Land Act (1913), and the Natives (Urban Areas) Act (1923).

3 For example, the Group Areas Act (1950), the Black Building Workers Act (1951), the Black Labour Relations Regulation Act (Black Labour and Settlement of Disputes Act) (1953), the Industrial Conciliation Act (Labour Relations Act) (1956), and the Environmental Planning Act (1967).
Legally prescribed affirmative action clearly influences how businesses ${ }^{4}$ (may) operate in post-apartheid South Africa. In other words, affirmative action amounts to state interference in the employment practices of business, which is motivated by the need to reduce inequality and to bring about more equitable representation in the workplace. State interference in business activities in order to reduce inequality may be merited if we accept that (at least some) businesses have some degree of moral culpability for previous injustices that resulted in inequality, or, at minimum, that businesses operating under apartheid benefited from these historical injustices. The Truth and Reconciliation Commission institutional hearings on the role played by business during apartheid found that "most businesses benefited from operating in a racially structured context", and that certain sectors, such as the mining industry, "were involved in helping to design and implement apartheid policies" (1998:58). The broad nature of these findings have been criticised for their "blunt, systemic, view of the relationship between business and apartheid", and for failing to pay sufficient attention to "gradations of moral behaviour under apartheid" (Nattrass, 1999:381). However, this does not entirely undermine the idea that at least some businesses have some degree of moral responsibility for post-apartheid inequality, or at least benefited from the unjust policies that contributed towards this inequality, and therefore have a corresponding moral obligation to contribute towards its rectification.

Even if we reject this conclusion, business may nonetheless have a moral duty to take action to reduce inequality in employment and income. This is because, as agents with great social power, it is generally accepted that business has a moral responsibility towards society in

4 Currently, the Employment Equity Act is applied to businesses with more than 50 employees or whose annual turnover is more than that set down in Schedule 4 of the Act (1998:3). 
general - in other words, to all stakeholders who can affect or be affected by business operations - and not only to shareholders. This includes both negative responsibilities (a duty to refrain from causing harm to society) and positive responsibilities (a duty to contribute actively to the good of society). This assertion would not exclude businesses that clearly have no moral culpability for apartheid, such as those established after 1994. In addition, business may have good instrumental reasons for wishing to see inequality reduced, given that on-going economic inequality contributes towards political instability, which, in turn, has a negative impact upon financial development (Roe \& Siegel, 2011).

Even if we accept that it is imperative to rectify inequalities resulting from past injustice, and that business has a role to play here, the question remains whether affirmative action is a morally appropriate means to achieve this goal. This remains controversial, and is frequently the topic of public debate. In this paper, we seek to examine this question by investigating possible normative grounds for affirmative action as redress for past injustice. ${ }^{5}$ We will do so by evaluating the possible implications of two paradigmatic theories of distributive justice, namely Robert Nozick's entitlement theory of justice and John Rawls's theory of justice as fairness. These two distributive models have been highly influential in twentieth century political philosophy, providing theoretical grounding for libertarianism and liberalism

5 As we are focusing here on interracial inequality in income distribution and employment resulting from historical racial discrimination, we will only examine justifications for race-based affirmative action. In other words, we do not focus on other forms of affirmative action that are included under the Employment Equity Act, such as affirmative action in favour of women or people with disabilities, although it is possible that our argument may also have implications for these forms of affirmative action. respectively. ${ }^{6}$ If we are unable to find grounds for affirmative action in either of these two theories, which offer competing normative frameworks for thinking about economic justice, this may imply that there is insufficient justification for affirmative action (at least as a form of redress), or that an alternative theoretical framework must be found in order to provide such justification.

\section{ENTITLEMENT, RESTITUTION, AND AFFIRMATIVE ACTION}

It may seem odd to seek normative justification for affirmative action in the work of Robert Nozick. Nozick is, after all, a libertarian who argues in Anarchy, State, and Utopia that "the minimal state is the most extensive state that can be justified", and that "any state more extensive violates people's rights" (1974:149). It therefore seems unlikely that one could discover in Nozick moral grounds for affirmative action, which entails extensive state interference in the employment practices of business.

Aside from the libertarian rejection of any state intervention beyond the protective services of the minimal state, it also seems likely that Nozick would take issue with the goals of affirmative action. The Employment Equity Act in South Africa is directed towards upsetting or revising the "disparities in employment, occupation and income within the national labour market" (1998:1), and seeks to bring about a less racially skewed and more egalitarian pattern of distribution. In other words, the current pattern of distribution and disadvantage is seen as undesirable, and a more equitable pattern of distribution is sought. However, Nozick rejects "patterned principles of distributive justice" that consider the "total

6 While we choose to focus on these two theories because of their profound influence, we acknowledge that other theories of distributive justice, for example, communitarian theories, are available. It is beyond the scope of this paper to explore these alternative theoretical models. 
picture of holdings" (1974:168). For Nozick, what matters is not the overall pattern of distribution in society, but rather whether each individual is entitled to what he or she has. As long as this is the case, any pattern of distribution is just, and there can be no justification for attempts to bring about (or maintain) a more egalitarian distributive pattern in society, as this would involve interfering in the free economic choices of individuals.

However, a Nozickean justification for affirmative action may possibly be found in the principle of "rectification of injustice in holdings" (1974:152). ${ }^{7}$ Despite Nozick's rejection of any patterned (re)distribution of holdings, he follows this rejection with an important parenthesis: "An exception is those takings that fall under the principle of the rectification of injustices" (1974:168). In order to interrogate whether affirmative action could be justified as just such an exception, we must provide a short overview of Nozick's entitlement theory of justice.

As described above, Nozick rejects any patterned principle of distributive justice. Rather, he argues for an entitlement theory of justice, which is historical, and which is concerned, not with a desired pattern of distribution, but rather with whether each individual is entitled to what he or she has. The entitlement theory is composed of three principles. Each individual is entitled to what he or she has, if: (1) a holding arises from a just original acquisition, or (2) a holding arises from a just transfer. The third principle (3) states that nobody is entitled to any holding that was not acquired in accordance with (1) or (2) (Nozick, 1974:151). Any pattern of distribution is just (no matter how unequal), as long as holdings have been acquired and transferred justly. As long as this is the case, any redistribution is morally illegitimate, including redistribution to bring about a more egalitarian distribution, as this would deprive individuals, whose holdings are redistributed, of what they are entitled to.

7 Such a move is not unprecedented - see, for example, Valls (1999).
However, this does not seem to imply that redistribution in the South African context is necessarily morally illegitimate. Indeed, such redistribution may be required as a matter of justice under the entitlement theory. It is the third principle that is relevant here. Where holdings in society have been acquired or transferred in a way that is incompatible with principles (1) and (2), entitlement is absent. In other words, Nozick acknowledges that:

Not all actual situations are generated in accordance with the two principles of justice in holdings: the principle of justice in acquisition and the principle of justice in transfer. Some people steal from others, or defraud them, or enslave them, seizing their product and preventing them from living as they choose, or forcibly exclude others from competing in exchanges. (1974:152)

In such situations, Nozick sanctions a principle of rectification. According to this principle, historical injustices in the acquisition and transfer of holdings must be rectified. To the extent that it is possible, we should try to bring about the situation (the distribution of holdings) that would have obtained, had the injustice not occurred (1974:153). If we agree that legally sanctioned racial discrimination during the colonial era and under apartheid gave rise to the flouting of the principles of justice in acquisition and transfer, then the resultant pattern of distribution that we are left with is unjust. Examples abound of this kind of racial discrimination in South African history. Aside from the questionable original acquisition of land by white settlers, and the long history of interpersonal discrimination, which undermined fair economic competition, legally sanctioned policies such as racially based land tenure (including forced removals) and job reservation would undoubtedly have flouted Nozick's principles of just acquisition and transfer. If these injustices had not occurred, we can assume that black South Africans, under conditions of fair competition, would have acquired a far greater share in the labour 
market and the economy, and that the pattern of employment and income distribution would have looked quite different today.

If this is indeed the case, and if the principle of rectification requires that we ought to attempt to bring about the distribution of holdings that would have realised, had injustices not occurred, then extensive state intervention to bring about such a distribution could be warranted, even under libertarian theory, which holds that, in the normal run of things, "the minimal state is the most extensive state that can be justified" (1974:149). Nozick admits as much, acknowledging that "past injustices might be so great as to make necessary in the short run a more extensive state in order to rectify them" (1974:231). It seems that this is precisely the situation that we are faced with in South Africa.

The question remains, however, whether affirmative action is a morally appropriate method for the rectification of historical injustice under the entitlement theory of justice. On the face of it, it seems that this could be the case. Nozick's full principle of rectification runs as follows:

This principle uses historical information about previous situations and injustices done in them (as defined by the first two principles of justice and rights against interference), and information about the actual course of events that flowed from these injustices, until the present, and it yields a description (or descriptions) of holdings in the society. The principle of rectification presumably will make use of its best estimate of subjunctive information about what would have occurred (or a probability distribution over what might have occurred, using the expected value) if the injustice had not taken place. If the actual description of holdings turns out not to be one of the descriptions yielded by the principle, then one of the descriptions yielded must be realized. (1974:152-153)

Affirmative action seems to be one way of achieving this (probably in conjunction with other sorts of interventions). As noted above, we can assume that, in the absence of the historical injustices perpetrated by the colonial and apartheid states, black South Africans would have acquired a far greater share in the labour market, and the inequalities in income distribution would have been far less. If affirmative action is able to bring about a situation in which previously dispossessed South Africans are better able to access the labour market and, particularly, management positions, along with the higher salaries that these positions attract, this would at least bring us closer to the situation (the pattern of distribution) that would have resulted in the absence of the identified historical injustices. ${ }^{8}$ Note that this moral justification for affirmative action is not concerned with bringing about diversity in the workplace, because such diverse representation is valuable in itself (an argument which is frequently raised in favour of affirmative action in South Africa ${ }^{9}$ ). Rather, it focuses only upon rectifying historical injustices in the acquisition and transfer of holdings, and would therefore no longer be morally justified once this rectification has been achieved (in other words, once one of the descriptions of holdings that would have come about in the absence of historical injustice has been achieved).

It seems then that a prima facie case can be made for affirmative action in South Africa, based on the principle of rectification. However, there is a further objection to be considered. The entitlement theory of justice is focused on

8 Of course, this assumes that affirmative action would indeed have this effect, rather than simply benefiting a small minority of black people who are already advantaged. This criticism was recently raised by Benatar, who argues that affirmative action in South Africa is "most likely to benefit those who were least disadvantaged" (2008:282). While this point deserves further consideration, space does not allow us to pursue this here.

9 For a discussion and critique of arguments for affirmative action that appeal to the value of diversity, see Benatar (2008:288-299). 
individual entitlement - Nozick's argument is premised on the primacy of individual property rights. The goal of rectification, according to this theory, is to ensure that the holdings of individuals conform to what would have been the case in the absence of historical injustice in the acquisition and transfer of holdings. In other words, it seems that "Nozick would recognise only individuals, not groups, as legitimate victims" of injustice (Van Wyk, 2001:181), and therefore that only individuals ought to be targeted for restitution under the principle of rectification. This also appears to be the implication of Nozick's strong rejection of patterned principles of distribution. Groupbased affirmative action, which requires that members of designated groups be given preference, as practised in South Africa, seems to undermine this focus on individual entitlement. Does this mean that affirmative action cannot be considered an appropriate method for rectifying historical injustices in acquisition and transfer? In order to answer this question, we need to look at some of the practical difficulties in applying the principle of rectification under Nozick's theory.

\section{RECTIFICATION IN PRACTICE: BACK TO PATTERNED DISTRIBUTION?}

While Nozick's principle of rectification is theoretically simple - identify where historical injustices in acquisition and transfer have occurred, and ensure that they are rectified in practice, the application of this principle is extraordinarily complex (Valls, 1999:301). This is especially the case in situations like the South African context, where innumerable injustices have occurred over a number of years, affecting vast swathes (indeed, the majority) of the population. The principle of rectification asks us to determine what pattern(s) would (probably) have occurred if these injustices had not taken place, and realise one of these patterns. However, if this requires us to determine what holdings individuals would have possessed in the absence of legally entrenched historical injustice in South Africa, this task seems to be so complex so as to be impossible. In some cases (for example, where forced removals took place), it is possible to identify specific victims who can be compensated. However, in terms of income and employment distributions, the multiple variables that have contributed towards the current state of affairs would be, for all intents and purposes, impossible to tease apart, and the impact upon the holdings of specific individuals would be impossible to quantify.

Unfortunately, Nozick provides little practical guidance as to how the principle of rectification should be applied. He leaves as open questions, for example, how far back we should go historically in terms of rectifying injustice, and how our obligations would differ in situations where descendants of the original beneficiaries and victims of injustice are involved, rather than the original actors, although he ventures that, ideally, "theoretical investigation will produce a [fully worked out] principle of rectification" (1974:152). However, he does acknowledge that there may be situations in which (a) there are multiple possibilities for descriptions of holdings that could have occurred in the absence of historical injustice, which would be difficult to choose between (1974:153), or (b) where historical information is insufficient to arrive at any full description of (individuals') holdings as they would have been in the absence of historical injustice (1974:231). In these situations, however, it seems that libertarian theory, with its strong focus on individual property rights, offers us no solution. Rather, Nozick suggests that we would need to revert to the principled patterns of distribution that he previously strongly rejected. In the first case, where there are multiple descriptions of holdings that could have occurred in the absence of historical injustice, he suggests that we may need to choose between these on the basis of "considerations about distributive justice and equality that I argue against" 
(1974:153). In the second case, where we lack sufficient historical information to determine the situation that would have pertained in the absence of historical injustice (which seems to be precisely the situation that we are faced with in South Africa), Nozick is forced to advocate for the adoption of Rawlsian principles which he has previously devoted a great deal of energy to debunking:

[A]ssuming that (1) victims of injustice generally do worse than they otherwise would and (2) that those from the least well-off group in the society have the highest probabilities of being the (descendants of) victims of the most serious injustice who are owed compensation ... then a rough rule of thumb for rectifying injustices might seem to be the following: organize society so as to maximise the position of whatever group ends up least well-off in the society. (1974:231)

This may provide a justification for groupbased affirmative action in the South African context, as opposed to individual restitution, but, paradoxically, only if affirmative action can be justified by Rawlsian principles (a question we will turn to next). What the preceding discussion does seem to show, however, is that the entitlement theory of justice is unable to cope with situations where distribution has been heavily skewed by historical injustice, as is the case in South Africa, without abandoning (at least in the short term) its commitment to the minimal state and to sacrosanct individual property rights - in other words, to its own libertarian foundations. In these situations, the entitlement theory is forced to rely upon patterned principles of distributive justice that it has previously situated itself in opposition to. In other words, under Nozick's theory, rectification is required in cases where it can be established that the principles of transfer and acquisition have been flouted. However, where we cannot identify precisely what the situation would have been in the absence of historical injustice, but it is clear that injustice has severely skewed the pattern of holdings in society, rectification may require that society should be organised "so as to maximise the position of whatever group ends up least welloff" (Nozick, 1974:231). Therefore, in societies marred by historical injustice, like South Africa, Rawlsian principles (or some other patterned principles of distribution) must first be applied, before Nozickian recommendations as to the minimal state and the protection of individual property rights can be instituted. For the time being, therefore (until rectification has been achieved), Nozick's entitlement theory of justice is of little use to us, as it cannot tell us how rectification ought to proceed without sacrificing its own premises.

\section{THE RAWLSIAN VIEW OF JUSTICE AS FAIRNESS}

Having demonstrated both why Nozick's theory cannot ground a defence of affirmative action as a form of redress (and thus of distributive justice) without abandoning its libertarian foundations, and why the issue of such a defence cannot be side-stepped in the South African context, we now turn to the question raised above, namely whether affirmative action can be justified by Rawlsian principles.

Before addressing this question, however, it is necessary to provide background to Rawls's conception of justice, as put forward in $A$ theory of justice (1971/1999). For Rawls, justice primarily concerns the question of fairness, and in order to determine what fairness implies, we must place ourselves in "the original position of equality" (1999:11), understood as "a purely hypothetical situation characterized so as to lead to a certain conception of justice" (1999:11).

Rawls contends that our sense of justice is influenced by our position in society (which, in itself, is largely the outcome of natural chance and historical contingency). The only manner in which we can counteract our prejudices and partisan interests is by hypothetically placing ourselves behind the so-called "veil of ignorance" (1999:11). Behind the veil of 
ignorance, we know nothing about ourselves or about our standing in society, which means that "all are similarly situated and no one is able to design principles that favour his particular position" (1999:11). Rawls therefore argues that we should choose the principles of justice in the original position, since it is "the appropriate original status quo" (1999:11), and is thus "an initial situation that is fair" (1999:11).

Rawls further postulates that, in the original position, we will act in a manner that is rational, conservative, and self-interested. In other words, we will not gamble with our futures, or sacrifice our interests for the interests of others. These conditions translate into a concern for the worst-off in society, as everyone would be worried that - once the veil is lifted - they would fall into this demographic. Given these basic shared views, Rawls argues that we would come to a consensus regarding two principles of justice: the first dealing with our basic liberties, and the second dealing with the distribution of wealth and income and institutional design. These principles read as follows:

First: each person is to have an equal right to the most extensive scheme of equal basic liberties compatible with a similar scheme of liberties for others.

Second: social and economic inequalities are to be arranged so that they are both (a) reasonably expected to be to everyone's advantage, and (b) attached to positions and offices open to all. (Rawls, 1999:53)

Principle 1 is referred to as the Equal Liberty (EL) Principle, Principle 2(a) is referred to as the Difference Principle (DP), and Principle 2(b) is referred to as the Fair Equality of Opportunity (FEO) Principle. Rawls gives preference to the first principle, arguing that "infringements of the basic liberties protected by the first principle cannot be justified, or compensated for, by greater social and economic advantage" (1999:53-54).

One last important remark to be made before turning to the issue of affirmative action is that Rawls presents his theory of justice as ideal theory. This means that he examines the conditions for justice in circumstances where on-going injustices are absent, and where present distributions are not the outcome of specific historical contingencies such as social engineering (Taylor, 2009:479). With reference to Rawls's conception of ideal theory, Thomas Nagel (2003:82) argues that ideal theory is helpful, in that it enables you to measure societies against the ideal of justice, and thereby allows you to characterise societies as unjust when they fall short of this ideal. However, Nagel also argues that ideal theory "does not tell you what to do if, as is almost always the case, you find yourself in an unjust society, and want to correct that injustice" (2003:82). This latter case falls within the scope of what Rawls terms "non-ideal theory", which clearly encompasses questions regarding affirmative action, defined as a measure "to deal with the unjust consequences of an unjust history" (Nagel, 2003:82).

Rawls's strict delineation between ideal and non-ideal theory explains why he never directly commentated on the justness of affirmative action, except for one passing comment on A theory of justice that appears in fustice as fairness: A restatement, which reads as follows:

The serious problems arising from existing discrimination and distinctions based on gender and race are not on its agenda... This is indeed an omission in Theory; but an omission is not as such a fault ... Whether fault there be depends on how well that conception articulates the political values necessary to deal with these questions. Justice as fairness, and other liberal conceptions like it, would certainly be seriously defective should they lack the resources to articulate the political values essential to justify the legal and social institutions needed to secure the equality of women and minorities. (Rawls, 2001:66)

The question of whether affirmative action can be justified by Rawlsian principles therefore hinges on whether Rawls's notion of justice as fairness 
does indeed hold the resources for normatively grounding affirmative action, especially in the South African context, and it is this question that will guide the remainder of the analysis. This analysis - which will largely be informed by Robert Taylor's detailed exploration of a Rawlsian perspective on affirmative action ${ }^{10}$ - will focus on three aspects: the scope of affirmative action interventions; EL and FEO, and the logical ordering of these principles; and the limit-conditions of non-ideal theories and their consequences for assessing the outcomes of social policies, specifically affirmative action policies.

\section{A RAWLSIAN PERSPECTIVE ON THE LEGITIMATE SCOPE OF AFFIRMATIVE ACTION}

Up to this point in the argument, affirmative action has been treated generically as a socioeconomic policy aimed at dismantling the entrenched patterns of racial inequality that characterise South African society in general, and the workplace in particular, and that are the legacy of the apartheid era. However, in order to determine whether Rawlsian principles can normatively ground these policies, it is necessary to distinguish between different categories of affirmative action. In this regard, we take as our lead Taylor's (2009:478-479) adaptation of Nagel's (1973:349-351, 356) taxonomy, which is cited below in condensed form:

10 The question of a Rawlsian account of affirmative action is not dealt with extensively in the extant literature. Apart from Robert Taylor's analysis, which is summarised here, and Samuel Freeman's short treatment of the problem in his book, titled Rawls (which is cited, in part, later on in this article), the only scholars to have published an extended treatment of the problem are Edwin Goff (1976) and Elisabeth Rapaport (1981). However, as pointed out by Taylor (2009:477), both these treatments are problematic, albeit for different reasons (namely, Goff's neglect of Rawls's partial-compliance applications and Rapaport's failure to distinguish between ideal and non-ideal conditions).
- Category 1: Formal Equality of Opportunity: ... requiring inter alia the elimination of legal barriers to persons of color, women, and so forth as well as the punishment of private discrimination against them.

- Category 2: Aggressive Formal Equality of Opportunity: self-conscious impartiality achieved through sensitivity training, external monitoring and enforcement, outreach efforts, and so forth as a possible supplement to category 1.

- Category 3: Compensating Support: special [measures] all designed to compensate for color- or gender-based disadvantage in preparation, social support, and so forth [in order] to help recipients compete more effectively.

- Category 4: Soft Quotas: 'compensatory discrimination in the selection process,' such as adding 'bonus points' to the selection of indices of persons of color or women in ... hiring processes, but without the use of explicit quotas.

- Category 5: Hard Quotas: 'admission [or hiring] quotas,' perhaps 'proportional to the representation of a given [historically oppressed] group in the population.'

The South African Employment Equity Act (1998) draws from most of these categories in framing its aims and its purpose, as set out in the Summary of the Employment Equity Act, 55 of 1998, issued in terms of Section 25(1). Statements from the summary that substantively support these categories are provided below:

- Category 1: "The purpose of this act is to achieve equity in the workplace by promoting equal opportunity and fair treatment in employment through the elimination of unfair discrimination"; and, "Affirmative action measures implemented by a designated employer must include measures to identify and eliminate 
employment barriers, including unfair discrimination, which adversely affect people from designated groups."

- Category 2: "Affirmative action measures implemented by a designated employer must include measures in the workplace based on equal dignity and respect for all people."

- Category 3: "Affirmative action measures implemented by a designated employer must include making reasonable accommodation for people from designated groups in order to ensure that they enjoy equal opportunities and are equitably represented in the workforce of a designated employer."

- Category 4 and 5: "Affirmative action measures implemented by a designated employer must include measures (i.e. preferential treatment [category 4] and numerical goals [category 5]) to ensure the equitable representation of suitably qualified people from designated groups ... and to retain and develop people from designated groups ..."

In order to interrogate whether the Employment Equity Act can be justified according to Rawlsian principles, it is necessary to determine whether, and to what extent, Rawls's theory can plausibly be used as normative support for these categories under both ideal and non-ideal circumstances.

Taylor (2009) argues that, given ideal circumstances, Category 1 affirmative action interventions will always be justified, due to FEO: FEO requires formal equality of opportunity, which means that, in principle, there should be no barriers to entry into the workplace (including barriers such as discrimination or monopolistic privileges). FEO also requires substantive equality of opportunity, which means that people of equal talent should have equal opportunities in life; and, furthermore, that it is the state's role to facilitate equal opportunities.
Although Category 2 interventions are more difficult to argue for under ideal circumstances, Taylor argues that these interventions would be justified only as a means to retain ideal conditions by preventing a backsliding into non-ideal past conditions (e.g., a history marred by racism and sexism), and by preventing certain current developments (e.g., large-scale immigration coupled with ethnic clumping in certain neighbourhoods) from leading to future non-ideal conditions. In ideal circumstances, Categories 3 to 5 interventions, however, threaten both formal and substantive FEO, and are therefore incompatible with Rawls's theory. In this regard, Samuel Freeman (2007:91) a Rawlsian scholar - states that:

under ideal conditions ... preferential treatment [is not] compatible with fair equality of opportunity. It does not fit with the emphasis on individuals and individual rights, rather than groups or group rights, that is central to liberalism.

What the above citation implies is that FEO is a necessary consequence of EL (which, to recall, is given lexical priority in Rawls's ideal theory). If we affirm the liberal view that individuals have equal liberties, then we are also committed to endorsing socio-economic institutions that engender these liberties to the extent that they promote fair equality of opportunity to all regardless of race, gender, class, etc. Under nonideal circumstances, however, the lexical priority of EL over FEO can, in some circumstances, be temporarily reversed, as argued below.

Rawls's non-ideal theory is contingent on one of two specific conditions: either partial compliance, in which on-going systematic injustices are carried out in the private or public sphere, or an economic and/or cultural historical legacy that negatively impacts upon present conditions (Rawls, 1999:215). Given these adverse conditions, Taylor (2009) argues that it seems plausible that a case can be made (1) to extend the scope of socio-economic policy beyond Category 2 interventions (which cannot address the legacy of past discrimination), 
in order to safeguard the moral and political equality of designated groups; and, (2) to reverse the order of EL over FEO (since, without substantive equality of opportunity, one can hardly claim equal liberty amongst people).

Taylor argues that the goal of non-ideal theory is to create a world in which ideal conditions can come about. However - in order to prevent non-ideal theory from functioning in a purely instrumental and utilitarian manner, in which questions of rightness and justness are sacrificed in the name of effectiveness - it is necessary to put certain constraints in place to ensure that the spirit of ideal theory is retained (even though the letter may be temporarily suspended).

Taylor follows Christine Korsgaard (1996) in her treatment of non-ideal theory, which is grounded in Rawls, but which also extends his position. In Creating the kingdom of ends, she identifies three conditions under which the lexical ranking of EL over FEO may be temporarily suspended, and which will ensure that "ideal [theory] will also guide our choice among nonideal alternatives" (Korsgaard, 1996:157). These conditions are: (1) the nonideal theory must be consistent with justicein-general, in which "the common good [is defined by] certain general conditions that are ... equally to everyone's advantage" (Rawls, 1999:217-218); (2) although the lexical order of EL over FEO may temporarily be reversed, any action must be undertaken with the goal of first securing EL (therefore preferencing FEO above EL is only justifiable if the goal is to promote EL); (3) the non-ideal theory must be consistent with the spirit of ideal theory.

In order to assess Category 3 to 5 affirmative action interventions in light of these constraints, it is first necessary to elaborate on the third condition. To act consistently with the spirit of ideal theory implies that any means undertaken to secure ideal conditions must appeal to liberaldemocratic principles. Taylor (2009:490) argues that "permitting violations of the spirit of ideal theory in addition to its letter may ... lead us to ask whether the nonideal theory can be wedded to its deontological ideal-theory counterpart without fatal tension." Otherwise put, violating the spirit of ideal theory constitutes a violation of procedural justice, which denotes "[a] fair procedure [that] translates its fairness to the outcome" (Rawls, 1999:75). If the procedure is not fair, then we have no guarantee of the fairness of outcome either (regardless of the goals that we set ourselves).

Applied to the categories of affirmative action, it stands to reason that Category 3 interventions are consistent with the spirit of ideal theory, since such interventions are aimed at liberating individuals by removing extraneous constraints that hamper fair competition. Drawing on Lyndon Johnson's metaphor, Taylor (2009:492) argues that "category 3 interventions remove the weights from the legs of participants in a race rather than rigging its rules." Category 4 and 5 interventions, however, violate the spirit of ideal theory, in that procedural justice (and the demands of FEO) is suspended through the enforcement of soft and hard quotas, in order to attain certain outcomes. If a fair procedure is not followed, fairness in the outcome is also not guaranteed, and it would be inconsistent with Rawls's theory to strive for fair outcomes whilst dismissing the need to establish fair conditions of competition.

The difficulty here is that we cannot know what a fair outcome would be, as a fair outcome is only guaranteed by a fair procedure. Category 4 and 5 interventions (soft and hard quotas) are directed towards bringing about a fair(er) outcome in cases where that outcome cannot be brought about by the use of Category 1 to 3 interventions alone. However, if these interventions are directed toward bringing about a fair outcome (in other words, a distribution that would have resulted in the absence of historical inequality), we must know what a fair outcome is, so that these interventions can be designed in such a way that they would indeed bring about, or contribute towards, this outcome - in this case, a just distribution in income 
and employment. However, as stated above, "we cannot ... know what a just distribution looks like unless we have actually carried out a just procedure" (Taylor, 2009:493). Therefore, Category 4 and 5 interventions, in aiming for a particular outcome, would be illegitimate - it would not be clear that the outcome that these interventions are directed towards would indeed be fair, as a result of their suspension of procedural justice and our lack of knowledge about the "counterfactual results of a 'clean' competition" (Taylor, 209:494). The attempt to establish a Rawlsian justification for Category 4 and 5 forms of affirmative action therefore finds itself faced with the same difficulty that we encountered in applying Nozick's principle of rectification in the South African situation we have insufficient knowledge about what the (fair) distributional situation would have been in the absence of historical injustice (in other words, had a fair procedure been followed).

The preceding analysis leads Taylor (2009:494) to conclude that:

rejigging competitive results on justice grounds is inevitably arbitrary and inconsistent with the spirit of FEO, at least if one accepts the interpretation of FEO as an application of pure procedural justice to the distributive domain of offices and positions, as Rawls very clearly does.

Therefore, whilst Rawls's theory allows us to normatively ground the legal clauses in the Employment Equity Act (1998) that support Category 1 to 3 interventions, the logical consequences of his theory lead us to morally reject legal clauses based on Category 4 and 5 interventions, i.e. soft and hard quotas.

\section{CONCLUSION}

In the foregoing analysis, we have shown that, in situations where distributions are heavily skewed due to historical injustices such as apartheid, Nozick's entitlement theory is of little use. While Nozick supports the need for redress in situations where the principles of justice in acquisition and transfer have been flouted, his principle of rectification cannot tell us what we ought to do in situations where it is difficult to determine what the distributional situation would have been in the absence of previous injustice. In these situations, Nozick suggests that we may be justified in adopting Rawlsian principles in order to address these issues. However, this implies abandoning, at least in the short term, the libertarian premises on which his theory is based.

We have also, however, demonstrated that Rawls's theory, which is premised on procedural fairness and equal liberty, can only normatively ground Category 1 and 2 interventions in ideal circumstances, and Category 1, 2, and 3 interventions in non-ideal circumstances. Category 4 and 5 interventions, which advocate the use of soft and hard quotas respectively, and which are legally prescribed in the Employment Equity Act (1998), are - at least from the perspective of Rawls's egalitarian theory - morally unjustifiable. The quota system suspends fair equality of opportunity in the name of securing equal liberties, but this represents a violation of procedural justice. The use of soft and hard quotas, therefore, cannot guarantee the justness of distributive outcomes, since these outcomes are themselves the consequence of unfair procedures, and because we have insufficient information about what the outcome of a counterfactual fair procedure would have looked like.

Faced with this argument, we are left with two possible outcomes: either we reject Rawls's conclusion on the basis that his theory is insufficient and simply does not go far enough in providing a normative foundation for the types of interventions (i.e. quotas) that are deemed necessary in order to secure racebased equality in a country like South Africa, or we accept Rawls's conclusion and reject the quota system for the reason that there is no sound moral justification for endorsing such a system. In this latter case, we would need to explore alternative means for the rectification 
of inequality. It is beyond the scope of this paper to give proper attention to these two alternatives. However, we offer the following provisional remarks in this regard.

The first alternative (i.e. the rejection of the Rawlsian position) necessarily implies that we need to find different criteria for grounding affirmative action policies. Apart from the equality argument, one popular argument often cited in support of affirmative action interventions is the diversity argument. Indeed, the landmark ruling in the Regents of the University of California v. Bakkes, in the U.S. Supreme Court in 1978, upheld affirmative action as one of several factors in college admission policies on the basis of the diversity argument. Similarly, the South African Employment Equity Act (1998:1) also cites diversity as one of the justifications for the Act, stating in the preface that affirmative action is necessary "in order to achieve a diverse workforce broadly representative of our people."

However, as Benatar (2008:288) has argued, " $[t]$ he more extreme the form of affirmative action the less it can be supported by the diversity argument." Given the fact that quota systems infringe on fair equality of opportunity, we are also of the opinion that a stronger criterion than that of diversity needs to be put forward in order to legitimise such infringements. Since the diversity argument is based on utilitarian as opposed to deontological grounds, in that it appeals to the value of diversity as a desirable outcome, it also cannot provide moral justification for the quota system, given the Constitutional enshrinement of moral equality before the law (which is clearly based on a deontological principle, rather than the utilitarian principle of the greater good). We therefore conclude that, in comparison to the equality argument, the diversity argument is weak. This is because the cost of forsaking the liberal values that undergird Rawls's theory and the South African Constitution, in order to promote a narrowly-conceptualised view of diversity, is too high.
Given this argument, we prima facie reject alternative one in favour of alternative two: we accept the Rawlsian conclusion that quota systems are morally unjustifiable, but we also strongly support the need for rectification of historical injustices, and, therefore, the exploration of alternative channels for restitution and redress. One such a channel is education.

Admittedly, the call for educational reform and the promotion of quality education is made often and loudly, but this does not detract from the urgent imperative to address this issue. In an article titled Poverty and inequality after apartheid, Jeremy Seekings (2007:13) states that, after unemployment, "[e]ducation is a second immediate cause of income poverty and inequality." He argues that factors such as lowgrade attainment and inadequately developed numeracy and literacy skills mean that most young South African school leavers are not equipped for semi-skilled or, especially, skilled employment. The main reason for this state of affairs is the poor quality of education in many South African schools, which he attributes to inadequate teaching conditions, inequalities in family backgrounds, inequalities in the classroom, and the constant restructuring of the curriculum post-1994. He further argues that low-quality education translates into "unemployment among the unskilled, and low earnings among those unskilled workers who are lucky enough to find jobs" (2007:15). As with inequality and poverty generally, the levels of education in South Africa are strongly correlated with race. In this regard, Servaas van der Berg (2011:135) notes that "[s]ome twothirds of the white matric-aged cohort complete matric, versus just over one-quarter of the black cohort, [and that] [i]f educational quality is considered, differences [between races] are even larger, as access to quality education remains highly skewed." Like Seekings, Van der Berg (2011:135) also remarks on the consequence of this situation, noting that "[e]specially among the young, many not completing high school 
are effectively excluded from the economic mainstream, given the way the labour market interprets educational attainment.”

It is evident that there is "a serious mismatch between the supply and demand for labour" (Seekings, 2007:15), and that this mismatch is primarily due to low-quality education (specifically amongst previously disadvantaged groups). Our contention and our conclusion is therefore that - given the high levels of inequality and unemployment in South African society, and the low level of skills in the labour market - business has a moral duty, as well as an instrumental reason, for helping to address this mismatch. We believe that the most effective way in which to do so is for business to invest in, and directly support, the educational sector and educational initiatives more strongly, and to ensure that equality and equal opportunity are furthered in the workplace through the implementation of affirmative action measures that seek to eliminate employment barriers (Category 1), to promote and enforce impartiality and an attitude of non-discrimination in the workplace (Category 2), and to remove extraneous constraints that hamper fair competition of previously disadvantaged groups (Category 3).

\section{REFERENCES}

Benatar, D. 2008. Justice, diversity and racial preference: A critique of affirmative action. The South African Law fournal, 125(2):274-306.

Freeman, S. 2007. Rawls. London: Routledge.

Goff, E. L. 1976. Affirmative action, John Rawls, and a partial compliance theory of justice. Cultural Hermeneutics, 4:43-59.

Korsgaard, C. 1996. Creating the kingdom of ends. Cambridge: Cambridge University Press.

Leibbrandt, M., Finn, A. \& Woolward, I. 2012. Describing and decomposing postapartheid income inequality in South Africa. Development Southern Africa, 29(1):19-34.
Lundahl, M. \& Petersson, L. 2009. Post-apartheid South Africa: An economic success story? UNU-WIDER: Helsinki.

Nagel, T. 2003. John Rawls and affirmative action. The Journal of Blacks in Higher Education, 39:82-84.

Nagel, T. 1973. Equal treatment and compensatory discrimination. Philosophy \& Public Affairs, 2:348-363.

Nattrass, N. 1999. The Truth and Reconciliation Commission on business and apartheid: A critical evaluation, African Affairs, 98:373-391.

Nozick, R. 1974. Anarchy, State, and Utopia. New York: Basic Books.

Rapaport, E. 1981. Ethics and social policy. Canadian fournal of Philosophy, 11:285-308.

Rawls, J. 2001. Fustice as fairness: A restatement. Cambridge, MA: Harvard University Press.

Rawls, J. 1999. A theory of justice, revised ed. Cambridge, MA: Harvard University Press.

Republic of South Africa, The South African Department of Labour. 1998. Employment Equity Act, No. 55 of 1998. [Online] Available: http://www.labour.gov.za [Accessed 1 September 2014].

Republic of South Africa, The South African Department of Labour. 1998. Summary of the Employment Equity Act, 55 of 1998, issued in terms of Section 25(1). [Online] Available: http://www.labour.gov.za [Accessed 1 September 2014].

Roe, M. \& Siegel, J. 2011. Political instability: Effects on financial development, roots in the severity of economic inequality. Journal of Comparative Economics, 39:279-309.

Seekings, J. 2007. Poverty and inequality after apartheid (CSSR Working Paper No. 200). Centre for Social Science Research, University of Cape Town.

South African Institute of Race Relations. 2013a. White men still top of the pay scale. [Press release]. [Online] Available: http:// irr.org.za/reports-and-publications/ 
media-releases/White\%20men\%20 still\%20top\%20of\%20the\%20pay\%20 scale.pdf/at_download/file [Accessed 1 September 2014].

South African Institute of Race Relations. 2013b. 2013 South Africa Survey. [Online] Available: http://irr.org.za/reportsand-publications/south-africa-survey/ south-africa-survey-online-2012-2013 [Accessed 1 September 2014].

Statistics South Africa. 2012. Census 2011.

[Online] Available: http://www.statssa. gov.za/publications/p03014/p030142011. pdf [Accessed 4 November 2014].

Taylor, R. S. 2009. Rawlsian affirmative action. Ethics, April:476-506.
Truth and Reconciliation Commission. 1998. Truth and Reconciliation Commission of South Africa Report, Volume 4, Chapter 2, 'Institutional Hearing: Business and Labour.'

Van der Berg, S. 2011. Current poverty and income distribution in the context of South African history. Economic History of Developing Regions, 26(1):120-140.

Van Wyk, M. W. 2001. Equal opportunity and equal liberty. Unpublished $\mathrm{PhD}$ dissertation. Johannesburg: University of Johannesburg.

Valls, A. 1999. The libertarian case for affirmative action. Social Theory and Practice, 25(2):299-323. 